\title{
Teachers' well-being from the social psychological perspective
}

\author{
Zawawi Zakaria, Yahya Don, Mohd Faiz Mohd Yaakob \\ School of Education and Modern Languages, Universiti Utara Malaysia, Sintok, Malaysia
}

\begin{tabular}{l} 
Article Info \\
\hline Article history: \\
Received Oct 9, 2020 \\
Revised Mar 8, 2021 \\
Accepted Apr 19, 2021 \\
\hline
\end{tabular}

\section{Keywords:}

Educational administration

Educational policy

Teachers' well-being

\begin{abstract}
School is an important organizational unit in a country. School is also the foundation of every country's education system. A harmonious working environment and a healthy relationship are very vital to ensure the high quality of teachers' work. Issues in the workplace can lead to low performance, job dissatisfaction, loss of happiness, stress, and many other mental health issues. Teachers' well-being is greatly influenced by comfortable, healthy, and happy conditions. Hence, this study aims to examine well-being among teachers in National Secondary Schools (SMK) and Government Funded Religious Schools (SABK) based on the quality of teachers' working life such as psychological, social, political, and economic needs. This was quantitative research with a survey method using questionnaires as the instrument. The respondents of the study comprised 300 teachers in a district in Kelantan, Malaysia. The respondents were chosen based on a random sampling technique. The results of the study showed that the level of teachers' well-being is high. There were no differences regarding the level of teachers' well-being between SMK and SABK.
\end{abstract}

This is an open access article under the CC BY-SA license.

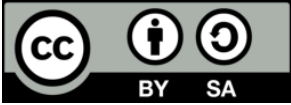

Corresponding Author:

Mohd Faiz Mohd Yaakob

School of Education and Modern Languages

Universiti Utara Malaysia

06010, Sintok, Malaysia

Email: mohdfaizmohdyaakob@gmail.com

\section{INTRODUCTION}

Malaysian Government implemented a balanced development approach between economic growth and society's well-being. Although there is no specific definition of well-being, the term is generally linked with the level and quality of life such as psychological, social, political, and economic aspects that may give benefits to society. According to Bretones and Gonzales [1], well-being is a form of psychological or internal quality of life. It involves several dimensions namely happiness, life satisfaction, self-esteem, self-efficacy, family life, job, education, and finances.

Teachers are a significant human resource that acts as the driving force of national education. Teaching session in schools nowadays is a dynamic process. Various constant changes in many aspects such as pedagogy, learning theory, curriculum, and educational purposes give a lot of challenges to the teachers [2]. Hence, teachers' well-being needs to be taken care of to ensure that they can perform their job efficiently. Veenhoven [3] concurred with this view by stating that well-being factors namely comfortable, healthy, and happy conditions can affect teachers' well-being.

In this study, teachers' well-being is seen from the perspective of the quality of teachers' working life. According to Rethinam and Ismail [4], the quality of working life is referred to the workplace efficiency that can develop employees' well-being and satisfaction in an organization. The quality of teachers' working life can ensure how far the school organization and working environment can support and meet the psychological, social, political, and economic needs by providing many growth and self-development 
opportunities. Schools need to play a role in providing a better and more efficient working environment to enhance the quality of teachers' working life. On the other hand, Maslow [5] stated that dissatisfaction with the quality of working life may influence many employees regardless of their status or position in an organization.

\section{LITERATURE REVIEW}

Teachers are emotional workers [6] and teachers' emotions have been found to influence their performance, self-efficacy, job satisfaction, burnout, and instructional effectiveness [7]-[11]. All teachers offended either the presence or absence [12]. According to Peters and Pearce [13], who in their study of Australian teachers, also stressed the importance of positive interaction and communication of school leaders in the resilience and well-being of teachers. With the rise of optimistic psychology in the research community, new ways of discussing discussions on teacher well-being are circulating [14], [15]. Teacher well-being has gained a lot of interest over the past few decades [16], [17] states that the positive ratio (ratio between positive and negative emotions) experienced by teachers will increase their work engagement, which in turn will positively affect well-being them. Many scholars found that personal resources (self-esteem, optimism, self-efficacy, and active coping) have been positively related to work engagement and psychological well-being and negatively associated with exhaustion [18], [19]. Positive emotions also cause upward spirals, as their positive consequences predict future increases in positive emotions and lead further to well-being [20]. Literature findings showing positive associations of work engagement with well-being and job satisfaction [21]-[24]. Meanwhile, literature showed teachers well-being are related to teacher's performance. Teachers' performance appraisal is a delicate process. On the one hand, it greatly influences the well-being of teachers [25]-[27] who can experience anxiety and pressure due to the evaluation [28]-[31]. Social networking services have been popular to increase teacher-student interaction, collaboration, and communication [32]. All of this element will increase teachers' well-being. The development and dynamics of education are demanding towards more integration [33]. Integration between teacher's workload and wellbeing are always debated.

\subsection{Problem statement}

Teachers in the 21st century always face stressful situations that can affect their well-being in the workplace. There are numerous conflicts and problems in the education field that still cannot be resolved until today. The issue of job satisfaction and workload are some hot topics among industrial workers and educators. Currently, many teachers often complain and feel dissatisfied with their job [34]. According to Kamarudin [35], this feeling of dissatisfaction occurs when an individual's need is not fulfilled. An unhealthy work environment not only affects the employees' motivation, but also employees' satisfaction, social relationship, performance, and health. Thus, several aspects need to be considered such as the provision of a conducive working environment that meets the teachers' well-being requirements at school, and the role of school leaders in managing the work environment and teachers' well-being.

Meanwhile, the People's Religious Schools (SAR) registration program is one of the efforts by the government to assist and empower religious schools in Malaysia. On 12th August 2008, a memorandum of understanding between Kelantan State Government and the Ministry of Education (MOE) has chosen 22 SARs with less than 100 students to be registered under the MOE as Government Funded Religious Schools (SABK). This program aims to empower religious schools under the Kelantan Islamic Foundation (YIK) to adhere to all aspects particularly career, salary, promotion, allowances, and more in line with mainstream education.

However, once the registration program is completed, there is a lack of research on teachers' wellbeing. Nevertheless, some studies indicate teachers tend to feel satisfied if their well-being and work environment are well taken care [8], [36]. Therefore, this article is important to identify teachers' well-being in SABK as well as SMK, which are public schools that receive full allocations from the government. There was also a study done by Lavy and Eshet [9], Adnan, et al. [37] on the teachers' commitment and climate at SABK schools in Kelantan. The results show that SABK teachers' commitment and climate are at a high level. Hence, further studies need to be conducted to indicate teachers' well-being and whether there are differences regarding the level of teachers' well-being between SMK and SABK.

The quality of teachers' working life should be examined to enhance teachers' well-being. Prior studies have shown that quality of working life has a significant impact on employee behavioral responses, namely job satisfaction, job engagement, job effort, job performance, desire to quit, organizational change, and organizational isolation [10], [38]. Therefore, this article is expected to discover the extent to which the needs of teachers are being met to improve their well-being. 


\section{RESEARCH METHOD}

This study used quantitative approach. The samples were determined using simple random sampling. A total of 300 teachers from seven schools, which are four SMK and three SABK schools in Kelantan were involved in this study. There were 220 respondents from SMK and 80 respondents from SABK. The concept of this study is based on the quality of teachers' working life as demonstrated [11]. According to Chen [11], Teachers' Work-Life Quality (KKKG) is the ability of the school organization and working environment in schools to develop and meet the teachers' needs based on four dimensions.

Teachers' well-being was measured by teachers' quality of life instruments adapted from Seligman [12]. The instruments consist of 25 items with four dimensions: 1) Political needs; 2) Social needs; 3) Economical needs; and 4) Psychological needs. There are two parts of the study instrument, namely part A and B. Part A covers the demographic aspect, while Part B assesses the teachers' well-being. The instrument used a five-point Likert scale, ranging from (1) strongly disagree to (5) strongly agree. For the interpretation purpose, the level of the mean score was coded into five levels: very low, low, medium, high, and very high.

\section{RESULTS}

This study investigated the teachers' well-being in SMK and SABK. The sample study comprises 300 teachers; with 220 SMK teachers $(73.3 \%)$ and 80 SABK teachers $(26.7 \%)$. Teacher profiles were divided according to gender, age, and grade in service. A total of 126 male teachers (42\%) and 174 female teachers $(58 \%)$ have participated in this study. According to age distribution, 27 respondents aged less than 30 years (9\%); 75 respondents aged between 31 to 40 years $(25 \%)$; 127 respondents aged between 41 to 50 years (42.3\%), and 71 respondents aged more than 50 years (23.7\%). Meanwhile for the job grade category, there were 56 DG41 respondents (18.7\%); 116 DG44 respondents (38.7\%); 79 DG48 respondents (26.3\%); 2 DG54 respondents (7\%), and 10 other grades (3.3\%). The demographic information can be seen in Table 1.

Table 2 shows that the level of teachers' well-being in both SMK $(\mathrm{M}=3.95, \mathrm{SD}=0.53)$ and SABK $(\mathrm{M}=3.86, \mathrm{SD}=0.48)$ is high. However, there are differences regarding the mean scores between SMK and SABK. It is indicated that the level of teachers' well-being for both types of schools has not yet reached a very high level.

Table 1. Respondents' demographic profiles

\begin{tabular}{lccc}
\hline \multicolumn{2}{c}{ Demographic } & Frequency & Percentage (\%) \\
\hline \multirow{2}{*}{ School type } & SMK & 220 & 73.3 \\
\multirow{3}{*}{ Gender } & SABK & 80 & 26.7 \\
& Male & 126 & 42.0 \\
\multirow{5}{*}{ Age (years) } & Female & 174 & 58.0 \\
& $<30$ & 27 & 9.0 \\
& $31-40$ & 75 & 25.0 \\
& $41-50$ & 127 & 42.3 \\
Grade in service & $>50$ & 71 & 23.7 \\
& DG41 & 56 & 18.7 \\
& DG44 & 116 & 38.7 \\
& DG48 & 79 & 26.3 \\
& DG52 & 37 & 12.3 \\
& DG54 & 2 & 0.7 \\
& Others & 10 & 3.3 \\
\hline
\end{tabular}

Table 2. Mean and standard deviation for SMK and SABK

\begin{tabular}{cccc}
\hline Variable & School types & M & SD \\
\hline \multirow{2}{*}{ Teachers' well-being } & SMK & 3.95 & 0.53 \\
& SABK & 3.86 & 0.48 \\
\hline
\end{tabular}

Table 3 shows a comparison between the mean levels of SMK and SABK for each dimension. It was found that the mean levels for all four dimensions are high and there are no differences between the mean levels for both types of schools. However, there are differences in the mean scores of SMK and SABK for each dimension. The SMK mean score is higher for all dimensions compared to SABK.

The social needs dimension has the highest mean score for SMK $(M=4.14, \mathrm{SD}=0.44)$ compared to SABK $(M=4.09, \mathrm{SD}=0.48)$, followed by economical needs dimension, with mean score for SMK $(\mathrm{M}=4.04$, $\mathrm{SD}=0.59)$ is higher than SABK $(\mathrm{M}=3.81, \mathrm{SD}=0.59)$. In addition, mean score for political needs dimension has indicated that SMK $(\mathrm{M}=3.87, \mathrm{SD}=0.50)$ has higher score than SABK $(\mathrm{M}=3.82, \mathrm{SD}=0.43)$. Finally, the mean score for SMK psychological needs dimension $(\mathrm{M}=3.75, \mathrm{SD}=0.58)$ is higher than $\mathrm{SABK}(\mathrm{M}=3.73$, 
$\mathrm{SD}=0.41$ ). The results showed that the well-being of teachers in SMK is better than in SABK, though it is not significant.

After performing the independent sample t-test analysis, the results in Table 3 show significant differences, $\mathrm{t}(298)=2.95, \mathrm{p}<.05$ between the mean scores for SMK and SABK in terms of economic needs dimension. There is a significant mean difference $(\mathrm{p}=.004)$ for this dimension between SMK and SABK. Meanwhile, for social, political, and psychological dimensions, there are no significant mean differences between both types of schools. It can be seen that the internal organizations of SMK and SABK are at the same level (high), particularly in the aspects of social relationships between colleagues, leadership, administrative management, respect, and self-esteem of every teacher.

Table 3. Mean differences and independent-sample t-test on dimensions based on schools

\begin{tabular}{|c|c|c|c|c|c|}
\hline Dimensions & School types & $\mathrm{M}$ & SD & $\mathrm{t}$ & $\mathrm{p}(\mathrm{Sig})$ \\
\hline \multirow{2}{*}{ Political needs } & SMK & 3.87 & .50 & \multirow{2}{*}{.841} & \multirow{2}{*}{.401} \\
\hline & SABK & 3.82 & .43 & & \\
\hline \multirow{2}{*}{ Social needs } & SMK & 4.14 & .44 & \multirow{2}{*}{.794} & \multirow{2}{*}{.428 } \\
\hline & SABK & 4.09 & .48 & & \\
\hline \multirow{2}{*}{ Economic needs } & SMK & 4.04 & .59 & \multirow{2}{*}{2.947} & \multirow{2}{*}{.004} \\
\hline & SABK & 3.81 & .59 & & \\
\hline Psychological needs & SMK & $\begin{array}{l}3.75 \\
3.73\end{array}$ & .58 & .358 & .759 \\
\hline
\end{tabular}

\section{DISCUSSION}

\subsection{Level of teachers' welfare in SMK and SABK schools in Pasir Puteh district}

Based on the findings, teachers in Pasir Puteh district have a high level of well-being in their working life. This is because all mean scores for each dimension are high. This is in line with the study conducted by Taxer and Frenzel [8], Yusof, Hashim and Ariffin [36] who found that teachers in MRSM Eastern Zone were satisfied with their well-being in the workplace. According to previous study [13], [39], the level of SLB B-C teachers' well-being in Cawas Klaten, Indonesia is also high.

The results of the study indicated that the dimension of the social need has the highest mean score than other dimensions. Hence, teachers' well-being in terms of social needs is very essential for school organizations, especially regarding the social relationships between teachers and colleagues, and the social responsibility of a teacher [11], [40]. The findings showed that teachers cooperate well with colleagues, trust their colleagues, and feel satisfied with their colleagues. Teachers' job satisfaction refers to the level of enjoyment that arises from their works or tasks, and it involves an individual's positive or negative feelings towards his or her job [41]. When positive feelings outweigh negative ones, they will increase their productivity and job performance. The results also indicate that teachers were allowed to be involved in the decision-making process and all group members' opinions were being considered. This is in line with Fatimah [42], which stated that the ability of teachers to work as a team, consult, collaborate, be supported, and trusted in the workplace can influence their overall well-being.

The results also show that the economic needs dimension has a high mean level. Economic status is one of the factors of individual happiness. SMK and SABK teachers agreed that their monthly income is sufficient for their expenses. Also, their monthly income allows them to own assets and practice charity by giving donations. It can be seen that teachers' well-being in terms of economic needs is good. Nordin and Thien [40] also stated that teachers' well-being can be observed on to what extent the school organization can fulfill teachers' economical needs particularly regarding their family dependency and daily expenditure. Insufficient income may lead to stress. This creates an opportunity for teachers to earn extra income and cause them to lose their commitment to teaching. Ekwulugo [43] mentioned that a teacher's commitment to teaching is a concept that reflects the psychological relationship between a teacher and his or her teaching. It can also reflect his or her willingness to show dedication to effective teaching, enthusiasm, and readiness to sacrifice more time for the students.

Besides, the political need dimension is at a high level for both types of schools. The work coordination between groups in schools is very good, teachers trusted each other, and teachers are satisfied with the honesty level of their colleagues. According to Nordin and Thien [40], the internal condition of a school organization can fulfill teachers' political needs in terms of democracy and autonomy, trust and honesty between colleagues, and fairness; all of which need to be in a good circumstance. The results of the study indicate that there are conflicts and competition among the teachers but there are still under control, based on the moderate mean score level. A very high conflict level may lead to anxiety, dissatisfaction, and frustration, thus also can decrease school performance. Tyree [44] highlighted that administrators are the 
main contributors to any political process. They need to be involved in conflict resolution, policymaking, and giving instructions to teachers, to ensure the relationships between teachers and administrators are harmony and good. The administrators of SMK and SABK also show a high level of mean scores, where most of the teachers are satisfied with the quality of management and they felt that work distributions among the colleagues are fair. Al-Buraey [45] stated that honest and fair environments give individuals positive expectations towards their colleagues' behavior. Thus, school administrators have successfully managed teachers efficiently and trust has important benefits for organizations [46].

The psychological need dimension showed the lowest mean scores compared to other dimensions. However, this dimension is still in the high-level category. From the results, it can be concluded that all schools appreciate teachers' abilities. Teachers felt respected and valued by the school administrations. The relationship between teachers and colleagues is also very good and no one felt isolated. This is consistent with Lee [19] study which mentioned that teachers who tend to do self-assessment are physically healthier than those who tend to do the bullying. However, findings also show that some teachers felt less appreciated by the school after they have completed their tasks. According to Nordin and Thien [40], the aspects of selfrespect, appreciation by colleagues and administrators need to be practiced regularly, so that teachers' selfesteem and values can be enhanced.

\subsection{Differences between teachers' well-being among SMK and SABK teachers in Pasir Puteh district}

Based on the findings, there are no differences between teachers' well-being in SMK and SABK. The mean levels for both types of schools are high, but there are differences in scores between the schools. The SMK mean score is slightly higher than SABK. This shows that SMK teachers have a more organized working environment and better facilities than SABK. However, SABK's internal organization is more positive since the transition process from SAR to SABK. Adnan, et al. [37] in their study found that the school climate for SABK in Kelantan is high. This is supported by Dewi [41] who highlighted that a positive climate is very essential in any school. He added that if the school has a good climate, hence the teachers and students will be more motivated and the teaching and learning activities can be done smoothly. There are no differences between the level of teachers' well-being in SMK and SABK due to similar work culture and curriculum in all schools in Malaysia. Fatimah [42] discovered that factors namely work environment and work culture have a positive relationship with employees' performance. Teachers that have a high level of well-being are an important asset to the school and the Ministry of Education because they will create a strong school climate for the benefits of education excellence. Generally, schools with a positive climate have good and attractive physical characteristics, good social relationships with colleagues, and a productive work environment [43].

\section{CONCLUSION}

Teachers' well-being in SMK and SABK in Pasir Puteh district, Kelantan is at a high level and there are no differences between these two types of schools. This indicates that after the transition process, SABK shows positive signs of competition for SMK. Teachers' well-being needs to be enhanced so that teachers feel happy, comfortable, and enjoy their working life at school. Therefore, this situation may produce good learning quality for students and improve teachers' well-being.

It is hoped that the results of this study can assist in providing a better understanding of theory and practice, especially for stakeholders in the education field. Besides, this study is expected to be applied by school administrators and policymakers at district, state, and national levels to measure the quality of teachers' working life in Malaysia as well as to enhance teachers' well-being. Teachers' well-being related to social networking services.

\section{REFERENCES}

[1] F.D. Bretones and M.J. Gonzales, "Subjective and occupational well-being in a sample of Mexican workers," Social Indicator Research, vol. 100, pp. 273-285, 2011.

[2] K. Louis and B. Smith, "Restructuring, teacher engagement and school culture: perspectives on school reform and the improvement of teacher's work," School Effectiveness and School Improvement, vol. 2, no. 1, pp. 34-52, 1990.

[3] R. Veenhoven How Do We Assess How Happy We are? Tenets, Implications and Tenability of Three Theories. Paper conference on 'New Directions in the Study of Happiness: United States and International PerSDectives', University of Notre Dame, USA, October 22-24, 2006.

[4] G.S. Rethinam and M. Ismail, "Constructs of quality of work life: A perspective of information and technology professionals," European Journal of Social Sciences, vol. 7, no. 1, pp. 58-70, 2007.

[5] A. Maslow, "A theory of human motivation," Psychological Review, vol. 50, no. 4, pp. 370-396, 1954.

[6] H. Yin, "The effect of teachers' emotional labour on teaching satisfaction: moderation of emotional intelligence," Teachers and Teaching, vol. 21, no. 7, pp. 789-810, 2015, doi: 10.1080/13540602.2014.995482. 
[7] A. C. Frenzel, "Teacher emotions," in R. Pekrun and L. Linnenbrink-Garcia, Eds., International Handbook of Emotions in Education. NY: Routledge, Taylor \& Francis Group, 2014.

[8] J. L. Taxer and A. C. Frenzel, "Facets of teachers' emotional lives: a quantitative investigation of teachers' genuine, faked, and hidden emotions," Teach. Teach. Educ., vol. 49, pp. 78-88, 2015, doi: 10.1016/j.tate.2015.03.003.

[9] S. Lavy and R. Eshet, "Spiral effects of teachers' emotions and emotion regulation strategies: evidence from a daily diary study," Teach. Teach. Educ., vol. 73, pp. 151-161, 2018, doi: 10.1016/j.tate.2018.04.001.

[10] J. Chen, "Efficacious and positive teachers achieve more: examining the relationship between teacher efficacy, emotions, and their practicum performance," Asia Pac. Educ. Res., vol. 28, pp. 327-337, 2019, doi: 10.1007/s40299-018-0427-9.

[11] J. Chen, "Exploring the impact of teacher emotions on their approaches to teaching: a structural equation modelling approach," Br. J. Educ. Psychol., vol. 89, pp. 57-74, 2019, doi: 10.1111/bjep.12220.

[12] M. E. P. Seligman, Flourish: A visionary new understanding of happiness and well-being. New York, NY: Atria, 2011.

[13] J. Peters and J. Pearce, "Relationships and early career teacher resilience: A role for school principals," Teachers and Teaching, vol. 18, no. 2, pp. 249-262, 2012, doi: 10.1080/13540602.2012.632266.

[14] S. Cherkowski and K. Walker, Teacher wellbeing: Noticing, nurturing, and sustaining flourishing in schools. Burlington. ON: Word and Deed Press, 2018.

[15] T. D. Dollansky, "The importance of the beginning teachers' psychological contract: A pathway toward flourishing in schools," Int. J. Leadership in Educ., vol. 17, no. 4, pp. 442-461, 2014, doi: 10.1080/13603124.2013.825012.

[16] P. Benevene, S. De Stasio, and C. Fiorilli, "Editorial: Well-being of school teachers in their work environment," Frontiers in Psychology, vol. 11, 2020, doi: 10.3389/fpsyg.2020.01239.

[17] P. P. Rusu and A. A. Colomeischi, "Positivity ratio and well-being among teachers. the mediating role of work engagement," Frontiers in Psychology, vol. 11, 2020, doi: 10.3389/fpsyg.2020.01608.

[18] D. Xanthopoulou, A. B. Bakker, E. Demerouti, and W. B. Schaufeli, "The role of personal resources in the job demands-resources model., Int. J. Stress Manag., vol. 14, no. 2, pp. 121-141, 2007, doi: 10.1037/10725245.14.2.121.

[19] Y. Lee, "JD-R model on psychological well-being and the moderating effect of job discrimination in the model: findings from the MIDUS," Eur. J. Train. Dev., vol. 43, pp. 232-249, 2019, doi: 10.1108/EJTD-07-2018-0059.

[20] B. L. Fredrickson and T. Joiner, "Reflections on positive emotions and upward spirals," Perspect. Psychol. Sci., vol. 13, pp. 194-199, 2018, doi: 10.1177/1745691617692106.

[21] B. Shuck and T. G. Reio, "Employee engagement and well-being: a moderation model and implications for practice," J. Leadersh. Organ. Stud., vol. 21, pp. 43-58, 2014, doi: 10.1177/1548051813494240.

[22] H. N. Perera, H. Granziera, and P. McIlveen, "Profiles of teacher personality and relations with teacher selfefficacy, work engagement, and job satisfaction," Pers. Individ. Diff., vol. 120, pp. 171-178, 2018, doi: 10.1016/j.paid.2017.08.034.

[23] J. Han, H. Yin, J. Wang, and J. Zhang, "Job demands and resources as antecedents of university teachers' exhaustion, engagement and job satisfaction," Educ. Psychol., vol. 40, pp. 318-335, 2019, doi: 10.1080/01443410.2019.1674249.

[24] X. Yan, J. Su, Z. Wen, and Z. Luo, "The role of work engagement on the relationship between personality and job satisfaction in chinese nurses," Curr. Psychol., vol. 38, pp. 873-878, 2019, doi: 10.1007/s12144-017-9667-8.

[25] I. Borrelli, P. Benevene, C. Fiorilli, F. D'Amelio, and G. Pozzi, "Working conditions and mental health in teachers: a preliminary study," Occup. Med., vol. 64, pp. 530-532, 2014, doi: 10.1093/occmed/kqu108.

[26] P. Benevene, L. Dal Corso, A. De Carlo, A. Falco, F. Carluccio, and M. L. Vecina, "Ethical leadership as antecedent of job satisfaction, affective organizational commitment and intention to stay among volunteers of nonprofit Organizations," Front. Psychol., vol. 9, 2018, doi: 10.3389/fpsyg.2018.02069.

[27] P. Benevene, M. M. Ittan, and M. Cortini, "Self-esteem and happiness as predictors of school teachers' health: the mediating role of job satisfaction," Front. Psychol., vol. 9, 2018, doi: 10.3389/fpsyh.2018.00933.

[28] P. Benevene and C. Fiorilli, "Burnout syndrome at school: a comparison study with lay and consecrated Italian teacher, Mediterr,” J. Soc. Sci., vol. 6, pp. 501-506, 2015, doi: 10.5901/mjss.2015.v6n1p501.

[29] D. Girardi, A. Falco, A. Piccirelli, L. Dal Corso, S. Bortolato, and A. De Carlo, "Perfectionism and presenteeism among managers of a service organization: the mediating role of workaholism," Test. Psychometr. Methodol. Appl., vol. 22, pp. 507-521, 2015, doi: 10.4473/TPM22.4.5.

[30] A. Falco, L. Dal Corso, D. Girardi, A. De Carlo, B. Barbieri, T. Boatto, et al., "Why is perfectionism a risk factor for workaholism? The mediating role of irrational beliefs at work," Test. Psychometr. Methodol. Appl. Psychol., vol. 24, pp. 583-600, 2017, doi: 10.4473/TPM24.4.8.

[31] R. Cuevas, N. Ntoumanis, J. G. Fernandez-Bustos, and H. Bartholomew, "Does teacher evaluation based on student performance predict motivation, well-being, and ill-being?” J. Sch. Psychol., vol. 68, pp. 154-162, 2018, doi: 10.1016/j.jsp.2018.03.005.

[32] L. Marzulina, A. Habibi, A. Mukminin, D. Desvitasari, M. F. M. Yaakob, and D. Ropawandi, "The integration of social networking services in higher education: Benefits and barriers in teaching English," International Journal of Virtual and Personal Learning Environments, vol. 8, no. 2, pp. 46-62, 2018, doi:10.4018/IJVPLE.2018070104.

[33] M. F. M. Yaakob, N. H. Hashim, M. R. Yusof, M. S. O. Fauzee, M. N. A. Aziz, H. Khun-Inkeeree, and K. Bing, "Critical success factors of sustainable leadership: Evidence from high-achievement school," Universal Journal of Educational Research, vol. 8, no. 5, pp. 1665-1675, 2020, doi:10.13189/ujer.2020.080502. 
[34] D. Elizur and and S. Shye, "Quality of work life and its relations to quality of life," Applied Psychology: An International Review, vol. 39, no. 3, pp. 275-291, 2011.

[35] Z. Kamarudin, "Teacher involvement in decision making, organization and work commitment," Master Thesis, Pulau Pinang: USM, 2007.

[36] Y. Z. Yusof, R. A. Hashim and T. F. T. Ariffin, "Modeling the relationship between well-being, well-being, and well-being in the workplace with teacher effectiveness collectively," Malaysian Journal of Learning and Instruction, vol. 12, pp. 177-204, 2015.

[37] M. Adnan, S. N. Ismail, S. Mohammad and H. Ibrahim, "School climate and teacher commitment in Kelantan Government Aided Religious Schools (SABK)," International Seminar on Generating Knowledge through Research, vol. 1, no. 1, pp. 699-708, 2016, doi: 10.21070/picecrs.v1i1.543.

[38] M. Arthy and M. Nadhini, "A study on quality of work life among the engineering college faculty members in Coimbatore district," International Journal of Management Research and Review, vol. 6, no. 8, pp. 1051-1057, 2016.

[39] A. R. Nordin, J. Hazri, O. Mohd Hashim, and A. Mohammad Zohir, "Soal selidik Kualiti Kehidupan Kerja Guru (Teacher Quality Work Life)," Universiti Sains Malaysia, 2009.

[40] A. R. Nordin and L. M. Thien, "Conceptualization and Construction of Teacher Work Life Quality Instruments," Jurnal Sains Humanika, vol. 9, no. 4, pp. 9-18, 2017.

[41] I. S. A. Dewi, "Subjective Welfare in Extraordinary School Teachers (SLB) B-C," (in Bahasa), Thesis, Universitas Muhammadiyah Surakarta, 2018.

[42] Fatimah, "Level of job satisfaction and organizational commitment among vocational college teachers: A structural equation model approach,” Master Thesis, Universiti Tun Hussein Onn Malaysia, 2014.

[43] V. Ekwulugo, "An Investigation into a Group of Inner and Outer London Secondary Teachers' Perceptions of their Own Wellbeing at Work," Thesis, Doctor of Education, Brunel University London, 2015.

[44] A. K. Tyree, "Conceptualising and measuring commitment to high school teaching," Journal of Educational Research, vol. 89, no. 5, pp. 295-304, 1996.

[45] M. Al-Buraey, Administrative development according to the Islamic perspective. Kuala Lumpur. Dewan Bahasa dan Pustaka, 1992.

[46] K.T. Dirks and D.L. Ferrin, "The role of trust in organizational setting,” Organs Sci., vol. 12, pp. 450-467, 2001. 